\title{
Development of Technical Reintroduction and Population Monitoring of Radiated Tortoises Astrochelys radiata in Southern Madagascar: Ampotaka
}

\author{
Soary Tahafe Randrianjafizanaka ${ }^{1,2,3,4}$ \\ ${ }^{1}$ Department of Animal Biology Faculty of Science, University of Toliara, Toliara, Madagascar \\ ${ }^{2}$ Turtle Survival Alliance (TSA), Fort Worth, USA \\ ${ }^{3}$ Turtle Survival Alliance (TSA), Antananarivo, Madagascar \\ ${ }^{4}$ Station d'Observation et de Protection des Tortues et de leur Milieux (SOPTOM), Gonfaron, France \\ Email: tahafinas@yahoo.fr, herilala@turtlesurvival.org, soptom@wanadoo.fr
}

Received 16 March 2014; revised 16 July 2014; accepted 23 August 2014

Copyright (C) 2014 by author and OALib.

This work is licensed under the Creative Commons Attribution International License (CC BY). http://creativecommons.org/licenses/by/4.0/

(c) (i) Open Access

\begin{abstract}
Ecological followed previous reintroductions of 262 juvenile Astrochelys radiata in the sacred forest Sirempo have revealed that individuals released directly without acclimatization left the site at $\mathbf{9 8 \%}$. The local habitat fulfilled all the conditions necessary for the development and survival of the species, and this site was recognized as distribution range of the species, but with a population whose abundance to decline over the last ten years. The research project "Development of Technical Reintroduction and Population Monitoring of Radiated Tortoises (Astrochelys radiata) in Southern Madagascar: Ampotaka" in a pre-identified natural environment conducive to their growth will preserve their viability, and predetermine site fidelity through an acclimation period before release. Realizing monitoring contributes to restoring self-sustaining populations in the wild, in cooperation and harmony with the manners and customs, and in trying to follow as much as possible the rigorous procedures already recognized by IUCN to prevent the transmission of diseases to wild populations and/or to prevent genetic mixing of different subpopulations in order not to endanger wild populations.
\end{abstract}

\section{Keywords}

Astrochelys radiata, Reintroduction, Ecological Monitoring, Ampotaka (South Madagascar)

Subject Areas: Earth \& Environmental Sciences

How to cite this paper: Randrianjafizanaka, S.T. (2014) Development of Technical Reintroduction and Population Monitoring of Radiated Tortoises Astrochelys radiata in Southern Madagascar: Ampotaka. Open Access Library Journal, 1: e279. http://dx.doi.org/10.4236/oalib.1100279 


\section{Introduction}

The crisis in 2009 in Madagascar where there was an increase in trafficking of natural resources and the radiated tortoise had not been spared, with over 3000 tortoises captured during that year [1]. These are generally favorable to traffic because of the atmosphere of instability and blurred decision-making within the administration periods, especially as attentions are also attracted to the environment. The crisis was manifested by the atmosphere of instability within departments, making officials reluctant to make firm commitments and this compounded habitat loss, illegal trafficking for marketing, the supposed medicinal practices and trade animals which leads to a reduction in the distribution of approximately 20\% over 25 years [2]-[4]. Tortoises are killed and eaten by Vezo and Antanosy.

Given the magnitude of the rate of decline of the species Astrochelys radiata [5]-[7], it is legitimate to take adequate measures exclusively to show that building operation Astrochelys radiata populations through reintroduction, in parallel with other measures on the environment because it's essential to prevent the extinction of this species. Reintroduction approach did not replace in any way the habitat restoration actions, and Dina introduced to fight against trafficking, but on the contrary it should be strengthened. It should thus establish in nature a species, sub-species or race viable, having disappeared or declined in the local natural environment; and the reintroduce species must be reintroduced into habitat range of previous natural distributions [8].

Our goals are generally to increase the chances of survival of the species over the long term in its range by choosing different approaches including the reintroduction, an approach that requires preparations and very specific steps. This strategy does not only concern the biological, socio-economic and legal considerations before reintroduction but also provide advice on the release itself and the activities to be performed after the release of individuals reintroduced [9].

As part of our research, it is to introduce Astrochelys radiata species entered to the reintegration into an environment for their development, develop natural environment, preserve their viability in sis pre-identified sites Ampotaka, realize acclimatation and restore self-sustaining populations in the wild; Figure 1 shows one reintroduced tortoise in Ampotaka.

In the end, we, and the environmental world:

- have the indicators to assess the success of a building in pre-identified natural environment sites.

- have a system of continuous environmental monitoring during the implementation of this reintroduction to ensure that we have adequate scientific information to continuously improve and correct approaches to reintroduction. It is in this context that fits the justification of this project to reintroduce the species captured in pre-identified sites and conduct scientific monitoring in cohesion with the acceptability of the surrounding communities reintroduction sites.

\section{Materials and Methods}

The sacred forest Sirempo (25 $6^{\prime} 51.54^{\prime \prime S}$, 44 $\left.40^{\prime} 12.24^{\prime \prime E}\right)$ as shown in Figure 2 located Ampotaka, and are respectively in the districts of Beloha, common Maronlinta Region Androy (intervention area TSA: Turtle Survival Alliance) is a sacred forest, managed by the community area close 62 ha (was the study area during this first phase of the research: this survey area consists of approximately 411 ha located on the east bank of the river Menarandra habitat. is typical dry deciduous forest characterized by the dominance of drought-tolerant species.

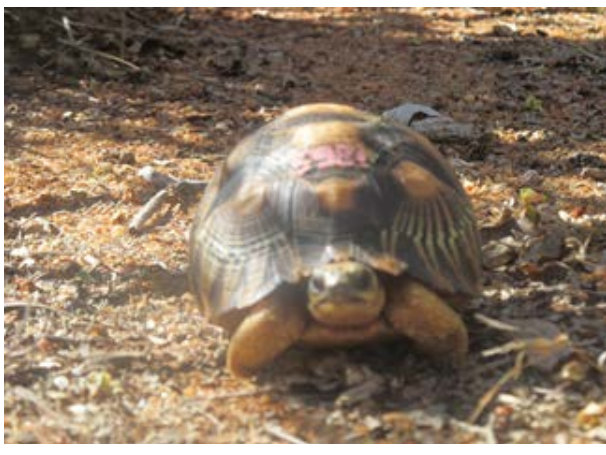

Figure 1. Astrochelys radiata in Ampotaka (photo by Soary RANDRIANJAFIZANAKA). 


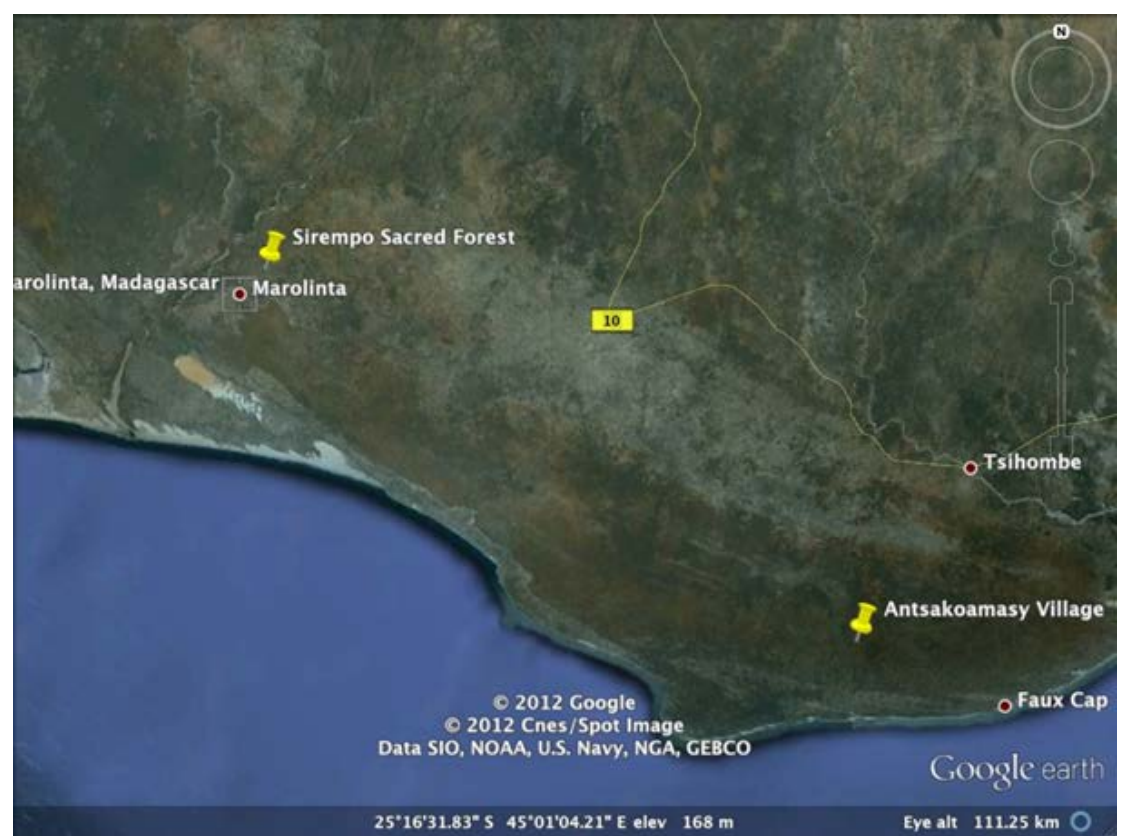

Figure 2. Study sites in southern madagascar.

Thus, the types of primary plant training are: dry forest degraded xerophytes scrub and grassy group grassy carpet "ahipoty” or Panicum sp “ahidambo" or Heteropogon contortus, or “debris Famanta” the soil is sandy clay containing no rock formation is characterized by limestone formations covered with sand on the surface making the rocky soil landscape, rocky surface. Stockings sandy plateaus or calcareous sand are the morphological entities in which we encounter in the forest Sirempo. The presence of water during dry also characterizes the forest landscape and the presence of several tombs and occasional traces of goat herds, the area can be considered largely intact. It is sacred because of the burial, and the existence of traditional laws. Thus, its status (place of burial) its characteristics and specific nature, forest Sirempo, has a very important interest in biogeography and conservation of biological and genetic diversity. Generally, the fauna and flora remain poorly known taxonomic point of view, only the observations noted the presence of several species mammal, reptiles, birds, still remain to be studied.

No reintroduction of tortoises has been made in the scientific standards in the wild, so far in Madagascar. Also the first place; 178 juveniles released to Ampotaka in September, and 193 juveniles released to Antsakoamasy in February, will be crucibles for testing assumptions, learn and learn about the processes and knowledge required for successful reintroductions. As well as during the raid, 84 were released at Ampotaka sp and 111 sp provided to Antsakoamasy released. Although the descent was conducted in November 2011 with the aim of performing a biological recognition of the natural habitat planned to release the seized funds, and monitoring and evaluation of previous reintroductions by:

Population study: by performing a known biological inventory stock, describe their preferred habitat, their variations and their intraspecific adaptation to local ecological status, ethology, the composition of their group, the size of their range, diet and shelter needs, foraging and feeding behavior, predators and diseases. In general, all the descriptions of the species in question are crucial to the whole process of reintroduction. Tortoises were surveyed along transect in each site: Sirempo: 7 transects traversed the morning from 5 am to 9 am and afternoon $16 \mathrm{~h}$ to $18 \mathrm{~h}$ at a speed of $2 \mathrm{~km} / \mathrm{h}$. At each observation of tortoises, the following data were recorded, length and width of the plastron and carapace, carapace height, sex, and approximate age (by counting the growth rings on the median dorsal scale. Other parameters measured include the perpendicular distance of the individual in relation to transects, time and temperature. The rate of activity of the animal (active rest) is also observed. To avoid recounting each individual, each tortoises (Aboriginal) observed was marked by a file according to the dialing mode.

The habitat evaluation: reintroductions should only take place if the needs related to habitat and landscape species are satisfactory, and are likely to remain so for the foreseeable future. Must considering the possibility 
natural habitat change since extirpation. The area should have sufficient carrying capacity to ensure I increase the reintroduced population and support a viable population (existence of an appropriate and consistent with the species ensuring the survival of the species habitat) in the long term. In each linear transect $1.5 \mathrm{~km}$, systematically, all $250 \mathrm{~m}$, quality of habitat, the appearance of plants, the parameters characterizing the micro habitat and vegetation within $5 \mathrm{~m}$ were evaluated ( ground cover, canopy opening, Representative vegetation). For vegetation, identified four $25 \mathrm{~m} \times 1 \mathrm{~m}$ were made along transect. The vernacular name of each foot plant is registered and phonology (flowering, fruit, leaf). The heights and diameters are taken as those having a diameter greater than $2.5 \mathrm{~cm}$. Much other information also collected, such as: orientation of the transect, specified using a compass, locating points of departure and arrival of the transect using a GPS $^{1}$ (beginning and end were marked by flags), medium altitude using an altimeter or even GPS, meteorological data such as the climate of the day, to characterize the conditions for carrying out biological surveys, the percentage of coverage ground in order to evaluate or analyze a micro habitat preference or use the turtle itself. This coverage can be achieved by the percentage of soil not covered by vegetation in a radius $\mathrm{R}=1 \mathrm{~m}$ around the individual. $100 \%$ ground cover means that the vegetation is extremely dense and a top view of the area $\Pi \mathrm{R}^{2}$ does not see the ground. The canopy percentage covers all of the clearings, allowing the sunshine to penetrate. The canopy can be discontinuous and allows the sun to penetrate the undergrowth. Representative vegetations specifying: the average heights of the thicket, emergent trees, litter, the substrate, the dominant plants, forest type (gallery forest, spiny forest).

Ecological monitoring: 178 species reintroduced later were also conducted to assess the fate of these populations. Indeed monitoring after release is required for all these individuals this aspect quite crucial can be done by direct methods (e.g. marking or telemetry, or indirect (e.g. informants, noting traces) the more appropriate, but in our case, we conducted follow-up visits by at transects.

\section{Results}

\subsection{Distribution and Abundance}

The daily course of seven transects with an average length of $1500 \mathrm{~m}$ each has identified a total of 2 and 4 native species reintroduced (Table 1). The abundance index is used if the number of individuals observed is low and Distance Program unable to estimate the density of the population. The abundance index is defined as the number of individuals encountered per unit distance traveled. It is given by the formula:

$$
\text { Abundance index }=\frac{\text { Number of individuals identified }}{\text { Distance }} \times 100
$$

In the forest of Sirempo relative abundance is 0.057 individuals $/ \mathrm{km}$ (average number of individuals counted per $\mathrm{km}$ ).

For sex ratio, we recorded both adults and juveniles (Table 2). Table 2 summarizes the sex ratio of individuals Astrochelys radiata. The sex ratio (males number divided by the number of females) in Sirempo is 0 which can be considered as an abnormal sex ration with nearly $0 \%$ and $100 \%$ of male's females.

In the site Sirempo, 33\% of individuals between 18 and 20 years, there are very few large tortoises. 33\% of youth and 33\% of adult south, suggesting a regular renewal of the natural population (Table 3).

The graph morphometric measurements $(\mathrm{cm})$ (Figure 3 ) represent below summarizes all individuals encountered in Sirempo. Since we did not encounter male individuals, a morphological comparison between male and female could not be done.

\subsection{Evaluation of Habitat}

The original habitats of the resident tortoises are forests or pressures do not influence the ecology of the species. Currently, by empirical observations can identify indigenous habitats, places and/or still contain tortoises. Table 4 shows the different types of habitats identified in transects:

These results show all soil types and specific area where the tortoises were inventoried vegetation: on rocky, stony, with litter as substrates "ahipoty” (Panicum sp) or "ahidambo" (Heteropogon contortus), for all individuals identified.

${ }^{1}$ GPS: Global Geographic System. 
Table 1. Distance performed during the survey.

\begin{tabular}{ccc}
\hline Sites & Effort $(\mathrm{km})$ & Nombre \\
\hline Sirempo & 10.5 & 6 \\
Total & 10.5 & 6 \\
\hline
\end{tabular}

Table 2. Sex distribution of individuals Astrochelys radiata.

\begin{tabular}{ccc}
\hline Sex & $\mathrm{n}$ & Frequency relative frequency \\
\hline Female & 4 & 0.7 \\
Male & 0 & 0.3 \\
Undetermined & 2 & \\
Total & 6 & \\
\hline
\end{tabular}

Table 3. Distribution of individuals Astrochelys radiata in different age.

\begin{tabular}{cccccc}
\hline & \multicolumn{3}{c}{ Age group } \\
\hline Site $n$ & Juv & Sub adult & Adulte \\
\hline & & & $(0-13)$ & $(14-17)$ & $(18->20)$ \\
Sirempo & 6 & & 2 & 2 & 2 \\
\hline
\end{tabular}

Table 4. Preferred habitat of tortoise.

\begin{tabular}{lll}
\hline \multicolumn{1}{c}{ Number of tortoise found on study area in Sirempo } & \\
\hline Rocky grounds & 0 \\
Low/high bush & 0 \\
Raketa & 4 \\
Field & 4 \\
Forest & 2 \\
\hline
\end{tabular}

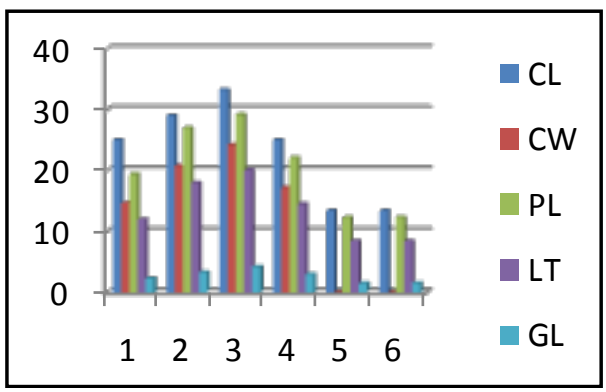

Figure 3. Morphometric (cm) of Astrochelys radiata.

- $66 \%$ of surveyed tortoises were found in vegetation dominated by raketa.

- Only $34 \%$ in the forest.

Note, however, that almost all the tortoises were observed in raketa led the empirical hypothesis assuming tortoises are located in areas likely to food (Raketa led, water (low field bush, rocky terrain, stony) is justified.

Thus, the forest is therefore not the only occupation of the turtle area. It can live in the forest as well as in open areas. Note that the forest grows generally on rocky soil, although some remain as clay or sandy places.

This finding is confirmed by all Aboriginal [10], Juvik observed the same phenomenon: "The turtle seems to prefer open areas with low vegetation such as shrub and meadow, probably because they offer more foods that forest areas." If tortoises then prefer open habitats (land Opuntia sp. Fields or culture) during dry seasons is that they are compared to foster the forest. Indeed, according to our key informants (guide, indigenous), the "sokake" 
(Astrochelys radiata) feed indeed succulent succulents such as Raketa or Opuntia sp.

\subsection{Ecological Monitoring of Reintroduced Species}

Ecological surveys were conducted on programs earlier reintroduction. They will take into account the positive and negative aspects of each of them in order to increase the chances of success and avoid repeat errors committed in the past because of a lack of knowledge or experience. Table 5 summarizes the stock of biological reintroduced in Ampotaka in question here.

As part of our research, ecological monitoring Astrochelys radiata has been achieved in the area of forests Sirempo release during the course of transects. In total, these observations have counted a total of 2 individuals (Table 5) on 6 inventoried (Figure 4), or 3\% of individuals releasing any particular group structure has been identified, thus, three months after the release, the 178 animals released, two have been recaptured.

A 3-day acclimatization test was performed on 84 sp reintroduced over the same period. This phase was implemented to tame the animal in its new habitat, were conducted in a fenced area, but it is still in the old habitat and the natural range of the species. Fences pre-release is fully removable and adjustable depending on the number of species and release characteristics of the terrain. These are round and fire wood $2 \mathrm{~m}$ tunnel type consisting of modular elements (4 m long, $4 \mathrm{~m}$ wide and $15 \mathrm{~cm}$ height) which are assembled end to end and secured by posts.

Young tortoises are transported delisted on release sites and put in pens pre-release in a group of 20 individuals. Since this is a first experience, we are not yet any really about time to accustom the animal to its new home at the point to stay permanently, from the experiments addiction was conducted during 3 days to Sirempo.

After released tortoises Sirempo after 3 days, the majority (79 sp) young juveniles were quickly scattered in the forest, a few (4 sp) only have remained in their enclosure, so it is best not release tortoises less than 50 days. However, it is likely. Throughout this period, they will be fed with natural resource location or make food surpluses if necessary.

\section{Discussion}

The release of species in their natural habitat is ideal designed for Astrochelys species radiata seizures.

Table 5. Ecological inventory release tortoise.

\begin{tabular}{cccc}
\hline & Activity release & & Monitoring activity \\
\hline Month release & Number of individuals released & Month follow & Number of individuals found \\
\hline Sept-11 & 178 & Nov.11 & 2 \\
\hline
\end{tabular}

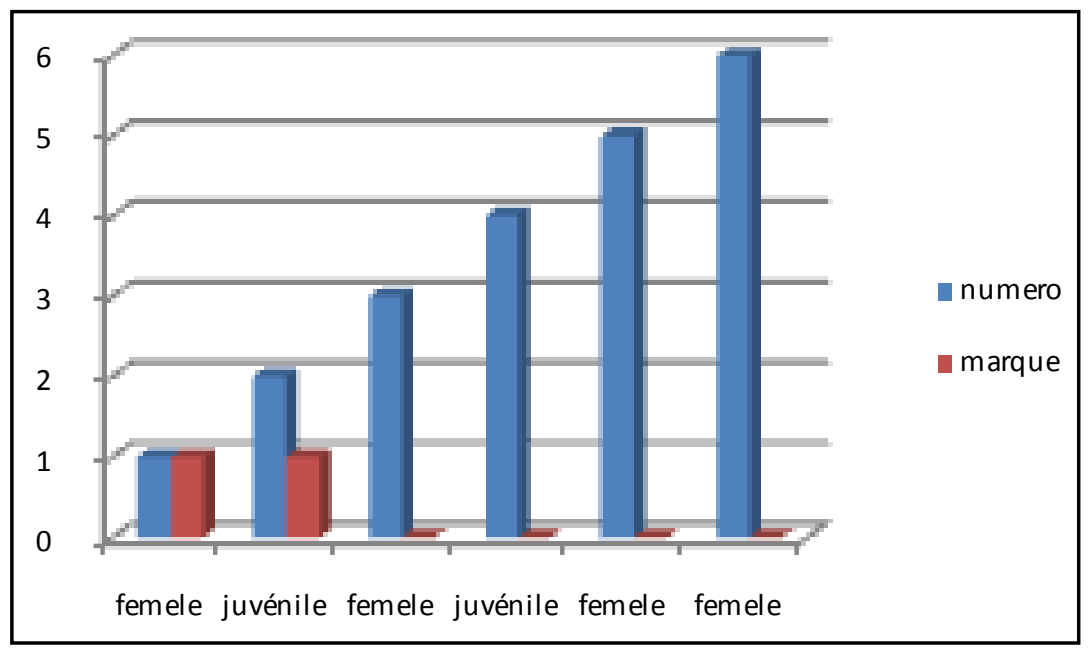

Figure 4. Ecological inventory of resident tortoise. 
And Geographically Sirempo is a place of natural distribution Astrochelys radiata, where native species still reside, protected under local DINA and status "sacred".

But the results of previous reintroductions awakening doubts about the compatibility of this new animal range. Reintroduced species do not reside in their place of employment, despite the efforts made $(10,500 \mathrm{~m})$ to find them in their new habitat. Social surveys reported that tortoises migrate to other places, some are found $25 \mathrm{~km}$ from the place of release, the other at $35 \mathrm{~m}, 10 \mathrm{~km}$ or more, their management vary if other take the southbound, take some the direction of north, east or west.

Several questions arise: "Why tortoises released not them stay in their place of rehabilitation but migrate elsewhere natural while this place is conducive to their development natural habitat? How were the results in other cases reintroduction? Migration is constant or it stabilizes after circumstances? Are there parameters that trigger this migration? Habitat or area of reintegration is it not appropriate to their development? Native species present they reside threats to these species reintroduced? Can I change bases have their engraving their new base on their new habitat will their site rehabilitation? The fingerprint phenomenon or impregnation is it valid in these chelonians after acclimatization phase?

\section{Hypothesis}

The release sites are environments conducive to the development of animals to reintroduce.

After acclimatization phase (pre-release) reintroduced animals will settle on their release sites without any dispersion (translocation of individuals without acclimatization phase results in a significant dispersion of animals, which is a factor unfavorable to the rapid fixation of a population. to reduce this dispersion, it is desirable to provide an acclimatization phase, a procedure that has been experienced in tortoises of the genus Gopherus in the United States [11].

The challenge of our research and the sites identified for reintroduction is a suitable habitat for its development. Challenge that takes us to the second part of the research.

\section{Proposal for a Strategy and Environmental Monitoring System Reintroduced Animals Ampotaka}

Ampotaka is in the range of the species where some wild individuals remain. (From a theoretical point of view, the release sites must harbor viable wild populations) according to time of year at which the releases occur. This site is good quality and has sufficient sources of food, and has a long-term protection provided (whether formal or informal title).

For the next reintroductions a draft protocol was in place before the release itself:

Collaboration between $\mathrm{DREF}^{2} \mathrm{RSO}^{3} / \mathrm{SOPTOM}^{4} / \mathrm{TSA}$, in which each entity has given a favorable opinion to the reintroduction (DREF), the SOPTOM its part provides 60 individuals required for this first experiment. Animals that will be accessible from the signing of the agreement between the entities concerned (SOPTOMTSA).

Note that this protocol included three distinct stages.

Preparation phase

- Signing of agreement.

- Selection of animals.

- Preparation of animals for future release (insulation, care, and suitable power) so that the animals are transferred in full health and well prepared.

Phase acclimatization

Placing two acclimatization enclosure 1 ha $(100 \mathrm{~m} \times 100 \mathrm{M}$ ) made of local wood (fantiolotse round wood), 40 $\mathrm{cm}$ in height so as not to trap external intrusions (cattle, goats and sheep) and containing a vegetation cover natural by way sufficient for 60 people for a period of 12 months for the first enclosure and 6 months for the second 6 months pens (30 individuals) and 12 months (30 individuals) food.

Phase release

Of releasing animals respectively after the above mentioned time (6 and 9 months) without rushing just by

${ }^{2}$ DREF: Direction Régional de l'Environnement et des forêts.

${ }^{3}$ RSO: Région Sud-Ouest.

${ }^{4}$ SOPTOM: Station d’Observation et de Protection des Tortues et de leur Milieux. 
putting an opening and let out quietly.

Phase tracking

Animals released and will be followed to determine the various issues on their migration or their attachment to the release site.

This monitoring program will be done in two ways.

- Scientific:

Where species release will be followed individually by VHF Transmitter for some better have more precision in habitat use, population difference distribution and distribution of reintroduced animals.

Telemetric monitoring of young species equipped with VHF transmitters may occur From Year 2 of the program and based on the results of 1 year, only a representative fraction of the released species will be equipped.

- Community:

Where previously trained community will monitor the animals tagged and released using sheets simplified collection.

After these experience, the reintroduction success is; the site fidelity, attachment to the site and their integration with the resident species. Other evaluation parameters are respectively (growth, habitat use, distribution, etc.).

\section{Conclusion}

The reintroduction is a complex process that should be handled in precautions because it may make the species more vulnerable to the external world. The first results have improved and the research protocol and the second part can certainly be pursued now. We hope that these future search results will be a basis for future reintroduction with local communities' agreement and national/international law.

\section{References}

[1] (2012) Programme de Conservation. WWF.

[2] Nussbaum, R.A. and Raxworthy, C.J. (2000) Commentary on Conservation of "Sokatra”, the Radiated Tortoise of Madagascar. Amphibian and Reptile Conservation, 2, 6-14.

[3] O’Brien, S., Emahalala, E.R., Beard, V., Rakotondrainy, R.M., Reid, A., Raharisoa, V. and Coulson, T. (2003) Decline of the Madagascar Radiated Tortoise Geochelone radiata Due to Overexploitation. Oryx, 37, 338-343. http://dx.doi.org/10.1017/S0030605303000590

[4] Irwin, M.T., et al. (2010) Patterns of Species Change in Anthropogenically Disturbed Habitats of Madagascar. Biological Conservation, 143, 2351-2362. http://dx.doi.org/10.1016/j.biocon.2010.01.023

[5] Pedrono, M., Smith, L.L., Clobert, J., Massot, M. and Sarrazin, F. (2004) Wild-Captive Metapopulation Viability Analysis. Biological Conservation, 119, 463-473. http://dx.doi.org/10.1016/j.biocon.2004.01.007

[6] Leuteritz, T.E.J., Lamb, T. and Limberaza, J.C. (2005) Distribution, Status, and Conservation of Radiated Tortoises (Geochelone radiata) in Madagascar. Biological Conservation, 124, 451-461. http://dx.doi.org/10.1016/j.biocon.2005.02.003

[7] Rasoma, R.V.J., Raselimanana, A.P., Ratovonamana, Y.R. and Ganzhorn, J.U. (2013) Habitat Use and Diet of Astrochelys radiata in the Subarid Zone of Southern Madagascar. Chelonian Conservation and Biology, 12, 56-69. http://dx.doi.org/10.2744/CCB-0909.1

[8] Tuberville, D. (2008) Evaluating the Success of Translocations for Turtle Conservation: A Case Study Based on Behavioral and Demographic Responses of the Gopher Tortoise, Gopherus polyphemus. Ph.D. Thesis, University of Georgia, Athens.

[9] IUCN (1998) Guidelines for Reintroductions. Prepared by the IUCN/SSC Re-Introduction SPecialist Group Switzerland.

[10] Juvik, J.O., Andrianarivo, A.J. and Blanc, C.P. (1981) The Ecology and Status of Geochelone yniphora: A Critically Endangered Tortoise in Northwestern Madagascar. Biological Conservation, 19, 297-316. http://dx.doi.org/10.1016/0006-3207(81)90005-7

[11] Tuberville, T.D., Clark, E.E., Buhlmann, K.A. and Gibbons, J.W. (2005) Translocation as a Conservation Tool: Site Fidelity and Movements of Repatriated Gopher Tortoises (Gopherus polyphemus). Animal Conservation, 8, 349-358. http://dx.doi.org/10.1017/S1367943005002398 